\title{
CONTRADIÇÕES DOS BIOCOMBUSTÍVEIS
}

\author{
Elias Antônio Vieira'; Bárbara Fernandes Vieira da Silva² \\ ${ }^{1}$ Geógrafo, pós doutorando, bolsista e pesquisador da FAPESP vinculado ao LABDES - Laboratório de Estudos Sociais \\ do Desenvolvimento e Sustentabilidade, UNESP, Rua Sebastião Roberto Bachur, 2.469, CEP 14.409-098, Franca (SP), \\ e-mail: <evieira371@gmail.com>; \\ ${ }^{2}$ Docente de Matemática e Pedagogia, Consultora Ambiental, Rua Cezário Gonçalves, 181, CEP 14.021-656, Ribeirão \\ Preto (SP), e-mail: <barbarafvsilva@hotmail.com>.
}

\section{RESUMO}

Este texto analisa as contradições relacionadas à perspectiva de se efetivar os usos dos compostos químicos de origem orgânica, denominados etanol e biodiesel, como energia renovável para diminuir a dependência energética de combustíveis fósseis.

Palavras-chave: biocombustíveis, espaço, meio técnico-científico-informacional, paisagem, território.

\section{CONTRADICTIONS BIOFUELS}

\section{SUMMARY}

This paper analyzes the contradictions related to the prospect of effective uses of chemical compounds of organic origin, known as ethanol and biodiesel, such as renewable energy to lessen dependence on fossil fuels.

Keywords: biofuels, space, medium technical-sicientific-informacional, landiscape, territory.

\section{CONTRADICIONES DE LOS BIOCOMBUSTIBLES}

\section{RESUMEN}

Este trabajo analiza las contradicciones relacionadas con la perspective de los usos efectivos de compuestos químicos de origen orgânico, Ihamado etanol y el biodiesel como energia renovable para reducir la dependência de los combustibles fósiles.

Palabras clave: biocombustibles, espacio; medio técnico, científico y la informática. paisaje, territorio. 


\section{INTRODUÇÃO}

O etanol e o biodiesel podem ser considerados não somente produtos para uso automotivo derivados de plantas, mas, sobretudo, um fato geográfico que tem origem nas relações entre os homens e destes com o espaço (VIEIRA, 2008). O objetivo deste estudo é utilizar uma ferramenta teórico-conceitual apropriada para analisar as contradições do fenômeno dos biocombustíveis como energia renovável. Deste modo, com base na revisão bibliográfica, entre outros dados levantados, se constatou que o etanol e o biodiesel podem se materializar, ao mesmo tempo, tanto na forma de soluções como de problemas sócio-espaciais.

\section{MÉTODOS E TÉCNICAS}

A base teórico-conceitual para a abordagem do tema fundamenta-se no uso dos conceitos espaço, meio técnico-científico-informacional, paisagem, território e na dialética que tem como um dos fundamentos o princípio da contradição (TRIVIÑOS, 1987).

Esses conceitos são definidos na literatura conforme segue. Segundo Lefébvre, citado por Martins Neto (2012), "o espaço é o lócus da reprodução das relações sociais de produção". Para Santos e Silveira (2004), o meio técnico-científico informacional é um meio geográfico em que o território inclui ciência, tecnologia e informação. Já, uma paisagem é, ao mesmo tempo, o somatório dos diferentes momentos do desenvolvimento da sociedade como resultado de uma acumulação de tempos (GEOMUNDO, 2012). Souza, citado por Spagnoli et al (2009 p. 78 e 96), por sua vez, entende o conceito de território como sendo "(...) definido e delimitado por e a partir de relações de poder"; "um campo de força, uma teia ou rede de relações sociais a par de sua complexidade interna, define, ao mesmo tempo um limite [...]: a diferença entre nós e os outros". Com relação à perspectiva dialética, os contrários coexistem (solução e problema, por exemplo) num fenômeno de tal modo que um não pode existir sem o outro (contradição), e quando um desaparece é porque o fenômeno sofreu uma transformação. Para Triviños (1987, p. 24) “[...] a oposição dos contrários, sua unidade e luta, é um dos postulados essenciais da dialética". Diante dessas considerações pode-se dizer que os aspectos contraditórios, como por exemplo, as vantagens e desvantagens estarão sempre presentes nos fenômeno geográficos, como é o caso do biocombustível.

\section{RESULTADOS E DISCUSSÃO}

No desenvolvimento da técnica norteadora do presente estudo buscou-se aplicar a base teórico-conceitual à realidade dos biocombustíveis.

Sendo assim, do ponto de vista estritamente técnico, estes produtos, enquanto fatos geográficos de natureza espacial e territorial foram concebidos no contexto da evolução da técnica, e dos recursos da informática e eletrônica, graças à associação desta com a ciência.

Quanto ao território vivem-se o tempo da existência simultânea de diferentes grupos de poder e corporações, atuantes no negócio de etanol e biodiesel, em distintos territórios num mesmo espaço geográfico nacional. Também se vive a etapa da aceleração das práticas sociais, ou melhor, das ações do dia-a-dia que conduzem a mudanças, pelo uso da técnica e do conhecimento 
científico (SANTOS; SILVEIRA, 2004), que, nesta década leva à correria na concretização dos resultados.

Do ponto de vista da contradição, estes produtos podem se materializar, ao mesmo tempo, tanto na forma de soluções como de problemas sócio-espaciais como, por exemplo: (i) o uso do território para a instalação, renovação ou ampliação da capacidade operacional de usinas ou agroindústrias de esmagamento de caules e grãos e refino (objetos técnicos e máquinas de produção), articulado aos meios ou infra-estruturas de comunicação como as estradas, ferrovias, hidrovias, os portos, terminais de armazenamento e distribuição, e sistemas de telecomunicações, entre outros objetos geográficos; (ii) a geração ou ampliação de impactos socio-espaciais por monoculturas (algodão, amendoim, cana-de-açúcar, dendê, girassol, mamona, pinhão manso, soja etc.); (iii) a redução da porção do território ocupada pela paisagem natural remanescente, mormente na região Norte do Brasil, agora artificializada pela sua pré-disposição aos usos da cadeia produtiva dos biocombustíveis; (iv) a produção do etanol e biodiesel, cuja tecnologia é dominada pelo Brasil, poderá contribuir para a redução das emissões de gases de efeito estufa que ampliam e aceleram as mudanças climáticas (JORNAL DO SENADO, 2007) e; (v) as medidas governamentais de redução de impostos e a ampliação das facilidades de crédito de automóveis podem contribuir com a renovação da frota antiga por veículos movidos a biocombustíveis, mas também acentuar as dificuldades de mobilidade nas cidades por falta de capacidade de suporte da infra-estrutura viária.

Em termos de processo histórico (TÁVORA, 2011) os biocombustíveis, no Brasil, apresentam os seguintes dados nas décadas recentes: 1975 - criação do Programa Nacional do Álcool (PROÁLCOOL); de 1977 a 1993 a adição de álcool à gasolina aumenta de 4,5\% para 25\%; 2003 - chegaram ao mercado os automóveis movidos a álcool e a gasolina com qualquer taxa de mistura; 2005 - lançamento do Programa Nacional de Produção e Uso de Biodiesel (PNPB); 2008 a 2009 - a adição de biodiesel ao diesel fóssil aumenta de $2 \%$ para $5 \%$, e é realizado o zoneamento agro ecológico da cana-de-açúcar visando disciplinar o uso e a ocupação do solo agrícola pelo vegetal (MARTINS NETO,2012).

Vale ressaltar que a política pública dos biocombustiveis do ponto de vista da contradição sofreu marchas e contramarchas durante o período histórico antes descrito. Ela esteve sob influência direta do nível de oferta, e preços, dos combustíveis fósseis. Com a descoberta de petróleo no pré-sal brasileiro e, para o futuro, a provável abundância do produto, não é errado dizer que o etanol e o biodiesel poderão sofrer nova contramarcha no país.

Quanto à efetivação desses produtos no mercado, o formato e o alcance de estratégias políticas, tanto no cenário nacional como internacional é de interesse de grupos econômicos de atuação nacional, regional e transnacional.

Nesse sentido, já se comenta que o Brasil tem potencial para atingir $40 \%$ do mercado de biocombustíveis e, para isso, o governo (e a sociedade) será levado a favorecer a abertura de fronteiras mais ao Norte do país, investir em logística rodoviária, ferroviária, hidroviária, portuária; de sistema de dutos, armazenamento etc. Do lado da petrolífera estatal brasileira, Petrobrás, se verifica uma oportunidade de ocupação desse segmento do comércio de energia, e de ampliação de sua influência e participação relativa no mercado de combustíveis, assim como de se apresentar numa posição de vanguarda perante os seus competidores e acionistas.

Em se tratando do uso do território para instalar objetos técnicos e máquinas de produção é um fato que demanda a aplicação de somas de capital, drenado da sociedade, sob a rubrica do Estado, destinadas a financiar a implantação ou renovação de infra-estruturas, em pontos específicos do território. Este fato beneficia direta, ou indiretamente, o setor privado e, muitas 
vezes, as classes sociais hegemônicas ligadas ao ramo. Os investimentos citados permitem esse setor a realizar parcerias para estabelecer seus fixos (objetos técnicos e máquinas de produção de etanol e biodiesel) e fluxos (mensagens, produtos e capitais corridos pelos meios técnicos).

Daí por diante, contudo, os fixos e fluxos estarão voltados não somente à exploração econômica dos biocombustíveis, mas também à modelação e administração das relações, do entorno, em favor de grupos empresariais, geralmente, localizados em outras regiões ou países.

Assim estabelecem-se as regiões do mandar, nos países considerados ricos, e as regiões do fazer, nos países tidos como pobres, perpetuando-se a exportação de matérias-primas (commodities) e importação de produtos acabados, pelos últimos. Esta forma de relação também é conhecida como dominante-dominado (SANTOS, 1997).

Além disso, a implantação de processos de tecnificação das regiões agrícolas em que predominam extensas áreas de plantio, de um só cereal ou vegetal (amendoim, café, cana-deaçúcar, soja etc.) voltado à exportação, denominadas de áreas de monoculturas (países ao Sul do Equador) pode originar diversos problemas. Contribui para a geração ou ampliação de impactos sócio-espaciais como a alteração da fisionomia das paisagens, passando a predominar a monotonia visual. Também prejudica a qualidade ambiental pela poluição acarretada devido ao uso intensivo, e manejo nem sempre cuidadoso, de adubos químicos e biocidas. Neste particular, para citar a emissão de poluentes da queima da palha da cana-de-açúcar, um estudo da Escola Superior de Agricultura Luiz de Queiroz, da Universidade de São Paulo, feito em Piracicaba, SP, mostrou que o valor médio de partículas, conhecidas por "carvãozinho", no ar da cidade fica acima do máximo permitido pelo CONAMA - Conselho Nacional do Meio Ambiente, ao longo do ano. E aumenta quase $40 \%$, no período da safra (JORNAL DA CANA, 2006). Estas partículas além de causar problemas atmosféricos, motivam incômodos e custos financeiros à população, em especial, das áreas urbanas pela sujeira que causam nas moradias, áreas de lazer, ruas etc., e pelo aumento do consumo e do custo da água exigido na limpeza.

O processo citado ainda favoreceu a migração rural-urbana intra e entre cidades e regiões brasileiras, o empobrecimento e a marginalização de parcelas de trabalhadores agrícolas e urbanos, sobretudo nas regiões tecnicamente atrasadas. Ainda, o uso progressivo de recursos da evolução tecnológica, como a mecanização das atividades agrícolas, o controle centralizado, de processos industriais (produção, recepção de grão ou vegetal, moenda, caldeira, destilaria etc.) interligados, via Internet, tem contribuído para a exclusão, temporária ou definitiva de trabalhadores desse setor econômico.

A despeito de existirem grandes unidades agroindustriais empregadoras, a diminuição de postos de trabalho também poderá ocorrer pela tendência de alianças e fusões entre empresas, mormente aquelas de proximidade geográfica, manifestada pela concretização de 37 negócios no período de 2000 a 2005. O fôlego à continuidade desse artifício econômico-financeiro está no fato de as usinas de açúcar, álcool, etanol e biodiesel, do Brasil, se constituir num ativo atraente, em particular, as de pequeno e médio porte. Está também nos objetivos de atingir maiores escalas econômico-financeiras dos principais produtores mundiais (JORNAL DA CANA, 2006; THIEME, 2011).

Quanto à pequena e média propriedade de produção de grãos e vegetais para biocombustíveis, se faz necessário o aperfeiçoamento da regulamentação, pelo Estado, das relações de trabalho, do acesso à propriedade da terra e de meios de integração agricultores nas modernas técnicas de produção e comercialização. Cumpre lembrar que os tipos de paisagens formadas por cultivares de subsistência ou comerciais para o abastecimento de mercados locais e, 
muitas vezes, regionais estiveram presentes desde que, no Brasil, predominava o tempo colonial ou do meio natural (CORREA, et al., 2001).

É importante também citar que o conjunto das atividades rurais tem contribuído para a degradação e redução das paisagens naturais do território brasileiro. Neste caso, deve-se lembrar o ordenamento territorial imposto pela política agrícola de cultivo de soja, para exportação do grão, na paisagem composta por trechos do bioma Cerrado no estado do Mato Grosso. As estratégias de produção desta cultivar, implementadas com conteúdo marcado, de forma preponderante, pelo uso do meio técnico-científico-informacional impuseram não somente a destruição da estrutura produtiva que já existia (SILVA, 2001), e de valores culturais e habilidades profissionais da população local, mas também um intenso processo de redução da paisagem natural.

Com o advento dos biocombustíveis e a demanda por terra, para o plantio de cultivares, que the servem como matéria-prima, os técnicos e os pesquisadores, as lideranças, o governo e a sociedade não podem concordar com a pressão exercida pelo mercado.

Desse modo, é imprescindível levar em conta o planejamento do uso e da ocupação do solo de modo a garantir a coexistência dessas paisagens com a agricultura, o mesmo valendo para o capital internacional e seus sócios nacionais com a ocupação do Cerrado, da Amazônia, do Pantanal etc.

Outra questão é merecedora de registro. Parte dos gases de efeito estufa (GEE) é emitida por combustíveis derivados do petróleo. O Brasil, apesar de ter avançado na área de biocombustíveis e de ser signatário do Protocolo de Kyoto, visando à redução desses gases, em 2006, estava entre os seus maiores emissores, ocupando o 4ㅇ lugar (HOUGHTON, 2008).

$O$ etanol e o biodiesel, por sua vez, a despeito da extensão e conexão dos problemas sociais e espaciais que sua expansão territorial pode representar, têm sido apresentados como combustíveis que minimizam o uso de derivados de petróleo e, portanto, reduz a emissão de GEE.

$\mathrm{Na}$ problemática socioambiental, é importante destacar ainda que, uma parcela, ainda restrita, das corporações que se dedicam à produção de açúcar, álcool, etanol e biodiesel procura desenvolverem procedimentos que minimizam os efeitos sócio-espaciais negativos de suas atividades empresariais. Como exemplo vale mencionar: (i) a utilização de área de reforma por outras atividades agrícolas (rotação de cultura); (ii) o controle biológico de insetos que atacam as plantas em substituição a agrotóxicos; (iii) o ajuste de variedades de cana-de-açúcar às peculiaridades do solo, conhecido no meio técnico como manejo varietal; (iv) a ampliação da área de colheita de cana crua; (v) a prática da adubação verde; (vi) a queima de biomassa (bagaço de cana) para a geração de energia elétrica; (vii) a adoção de estratégias de redução e reciclagem de resíduos (torta de filtro, vinhaça etc.) e de reuso da água; (viii) a destinação de dinheiro para pesquisas; (ix) a busca do crescimento agrícola vertical (salto de produtividade na mesma porção de terra); (x) a criação de programas de qualificação da mão-de-obra; e (xi) a introdução de práticas que atendem ao princípio da responsabilidade social corporativa, como a doação de recursos materiais, e financeiros, para programas socioculturais e esportivos, entre outras.

\section{CONSIDERAÇÕES FINAIS}

Neste artigo verificou-se que o uso dos biocombustíveis vem sendo defendido por governos e corporações nacionais e transnacionais por um discurso socioambiental em favor de interesses econômicos de grupos hegemônicos. Esta estratégia pode ser mais bem visualizada no 
argumento de que tais produtos se apresentam como alternativas para alimentar a indústria automobilística e reduzir, ao mesmo tempo, a poluição pelo uso de combustíveis fósseis.

Tal argumento, entretanto não considera a capacidade de suporte da infra-estrutura viária do Brasil para admitir o crescimento contínuo da produção de veículos. Também se constatou, por um lado, a manifestação de discursos contrários à produção e uso do etanol e do biodiesel tendo em vista os problemas sócio-espaciais, sobretudo, os econômico-ambientais, pelo agravamento da poluição, exclusão social e pela perspectiva de a demanda por terra, dos cultivares de biocombustíveis, afetar a segurança alimentar mundial.

Diante disso, pode-se inferir que a realidade socioespacial do mundo quanto à diminuição da dependência energética de combustíveis fósseis e a solução da poluição e seus efeitos nas mudanças climáticas, é muito mais complexa do que se imagina. Talvez a melhor saída para esta problemática esteja na ampliação do debate sobre a produção e o consumo em geral não apenas entre os governantes, técnicos e grupos empresariais, mas, sobretudo com a sociedade.

\section{AGRADECIMENTO}

O primeiro autor agradece o apoio recebido da FAPESP - Fundação de Amparo à Pesquisa do Estado de São Paulo, a uma pesquisa maior, que possibilitou a produção deste artigo.

\section{LITERATURA CITADA}

CORREA, A. C. B.; WOODWARD, S.; DE BIASE, I. Tipologia de paisagens de pequenas propriedades familiares e sua relação com a fisiografia do planalto da Borborema, Nordeste do Brasil. In: ENCUENTRO DE GEÓGRAFOS DE AMÉRICA LATINA. 8. 2001. Santiago do Chile. Resumenes. Santiago do Chile, 2001. 741 p.

GEOMUNDO. O conceito de paisagem. Disponível em: http://<www.geomundo.com.br/geografia>. Acesso em: 23 mai. 2012.

HOUGHTON, R.A. Carbon Flux to the Atmosphere from Land-Use Changes. In TRENDS: A Compendium of Data on Global Change, 2008. Disponível em: <http://www.ipam.org.br>. Acesso em: 27 mai.2012. JORNAL DA CANA. Notícias do setor sucroalcooleiro. № 156. Ribeirão Preto, dezembro/ 2006. JORNAL DO SENADO. Especial. Fator humano no centro do debate. 19 a 15.03.07. Brasília, 2007.

MARTINS NETO, J. Conceitos: espaço, lugar e território. Disponível em: <http://www.webartigos.com/artigos >. Acesso em: 23 mai. 2012.

SANTOS, M. Técnica, Espaço, Tempo - globalização e meio técnico-científico-informacional. 3ạ. ed. São Paulo: Hucitec, 1997.

SANTOS, M.; SILVEIRA, M. L. O Brasil: território e sociedade no inicio do século XXI. 6a. ed. Rio de Janeiro: Record, 2004.

SILVA, C. A. F. da. Ordenamento territorial do complexo soja no cerrado brasileiro. In: ENCUENTRO DE GEOGRAFOS DE AMÉRICA LATINA. 8. 2001. Santiago do Chile. Resumenes. Santiago do Chile, 2001. 741 p.

SPAGNOLI, M. V.; ALVES, F. D.;FERREIRA, D. A. O. O conceito de território e região nas políticas públicas: uma discussão inicial para o entendimento dos Territórios da Cidadania. In: V ENCONTRO DE GRUPOS DE PESQUISA. 25 a 27/11/2009. Anais. Santa Maria (RS): UFSM, 2009.

TÁVORA, F. L. História e economia dos biocombustíveis no Brasil.Brasília: CECS, 2011.

THIEME, M. E. Setor sucroalcooleiro deve ter novas fusões e aquisições. Disponível em:<http://veja.abril.com.br/noticia> . Acesso: 23 maio 2012.

TRIVIÑOS, A. N. S. Introdução à pesquisa em ciências sociais. São Paulo: Atual, 1987.

VIEIRA, E. A. Combustível de vegetais: reflexões sobre os aspectos sociais e espaciais. Revista Geografia, Rio Claro, v. 33, no 1, jan/abr. 2008. 